\title{
A Simulation Study of Urban Public Transport Transfer Station Based on Anylogic
}

\author{
Weiwei Liu ${ }^{1}$, Fu Wang ${ }^{1}$, Chennan Zhang ${ }^{1}$, Jingyu Zhang ${ }^{2}$, and Lei Wang ${ }^{3^{*}}$ \\ ${ }^{1}$ Business School, University of Shanghai for Science and Technology, China \\ [e-mail: weiweiliu@usst.edu.cn, 203661056@st.usst.edu.cn, cindyzcn@126.com] \\ ${ }^{2}$ School of Computer \& Communication Engineering, Changsha University of Science \& Technology, China \\ [e-mail: zhangzhang@ csust.edu.cn] \\ ${ }^{3}$ School of Civil Engineering, Changsha University of Science \& Technology, China \\ [e-mail: leiwang@csust.edu.cn] \\ *Corresponding author: Lei Wang
}

Received December 28, 2020; revised February 1, 2021; accepted February 9, 2021;

published April 30, 2021

\begin{abstract}
With the increase in the population of our cities and the rapid increase in the number of private cars, urban traffic has become more and more congested. At this stage, urban public transportation has become one of the main ways to improve urban traffic congestion. Aiming at the problem of how to improve the basic capacity of buses in multi-line transfer stations, this paper conducts simulation research based on anylogic software. Through microsimulation analysis of vehicles entering, stopping, and exiting the station, combined with the delay model theory, the vehicle is given Stop organization optimization and station layout improvement methods, so that vehicles can run in the station more stably, smoothly and safely. Case analysis shows that applying this method to the roadside parking problem, the main and auxiliary bus stations have a significant improvement in operating capacity compared with the conventional tandem double bus stations, and the service level of the main and auxiliary bus stations has been significantly improved.
\end{abstract}

Keywords: Public Transport, Simulation, Traffic Flow Characteristics, Service Level 


\section{Introduction}

Bus station is an important part of urban bus transit system, is the throat of urban public transport system, bus station capacity not only determines the capacity of the city bus system, but also affects the efficiency of road near the station [1]. Reasonable organization of the traffic within the bus station, the flow of people, is the fundamental guarantee to improve the public transport site [2]. The related work can be appied in some new emerging scenarios [3-6].

According to different platform settings, bus stops can be divided into four categories: straight-line bus stops, harbor-style bus stops, straight-line separated bus stops, and multi-bay bus stops. Multi-line stops are currently relatively common forms of stations, such stations bus and passenger traffic is very large, if the setting is unreasonable, it is easy to lead to serious vehicle queuing phenomenon during peak hours, become the bottleneck of the entire road [7, 8]. In 2006, Lv Lin [9] first gave the principle of location of bus stations, and analyzed the impact of linear stations and harbor-style stations on traffic flow, and established a mathematical model of the speed of social vehicles and bus platform occupancy time and road traffic flow, which has a more solid theoretical basis in determining the better site form. Using the queuing theory and the probability analysis method of head-time distance, combined with the station pass capacity, the station line capacity adapted to our country is given [10]. By using the traffic speed model, the characteristics of the main line and the ordinary harbor station at different levels of traffic flow are studied, and the dimensions of the site area are optimized. In the same year, Ge Hong-wei [11]the impact of public transport stops on the capacity of other traffic flow models and bus stop delay models, on the basis of comprehensive consideration of the characteristics of bus stops, developed a more rigorous optimization technology and methods. Besides, the similar modeling research has been studied in various fields [12-14]. In terms of research on the optimization of bus stop spacing and location selection, S. C. Wirasinghe [15] of Canada systematically discussed the optimization and determination of the average bus stop spacing in 1981, and the study took into account the bus operating cost and passenger travel expenses. , The optimization model is established with time as the unit of measurement, but because many parameters of the model are difficult to determine, its practicality is not strong. In 2001, Anthony A. Saka [16] proposed an optimization model for the average distance between stops based on bus operating cost constraints.

In terms of bus station location selection and station distance optimization, foreign research work began as early as the 1950s and 1960s, but in the early stages of the study mainly qualitative analysis, gradually to the beginning of the 1980s began systematic research, resulting in a number of preliminary optimization models [17-19]. Antony.A.Saka [20] proposed an optimization model for the average distance between stops taking the bus operating cost as a factor. The bus operating time is divided into acceleration and deceleration time, time to stop at the platform, smooth running time and other running time, etc. He did not consider the operation of buses at unsignalized intersections, and the model does not have general applicability. In terms of the impact of bus stops on the subsequent traffic flow, Sam Yagar [21]controls the time of the signal intersection and the arrival time of the bus, analyzing the impact of delays on the intersection by buses parked upstream of the intersection in different situations. Arasan and others [22] have given a simulation model of micro-traffic flow through a simulation technique to study the impact of bus stops on mixed traffic flow, and verified the reliability and practicality of the model through practical cases, and analyzed the influence of the geometric characteristics of harbor-type bus platforms and non-harbour-type bus platforms on the speed of other vehicles in road traffic flow. 


\section{Analysis of Time Delay in Bus Stop}

\subsection{Arrival Delay Characteristics and Evaluation Indicators}

Based on the queuing theory, a model of subsequent social vehicle delays during the bus stop process can be established [23]. When the bus starts to decelerate and enter the station, the social vehicles in the rear want to overtake the bus, they need to wait for the adjacent road section to provide enough space to insert the vehicle. When the bus stops completely, if the social vehicle still cannot After the lane change is completed, traffic will gather behind the bus, which will cause queuing block [24].

Because the traffic flow satisfies the three conditions of stability, generality and no aftereffect. Among them, the stability of the traffic flow refers to the fact that other external interference factors basically do not exist during the operation of the traffic flow, and it is in a relatively stable state; the generality of the traffic flow refers to the overall traffic flow as a macroscopic whole. No particularity; the inefficiency of traffic flow means that if the state of the vehicle in operation is known, the development and change of the process from this stage onwards is only related to the state of this stage, but is related to the process experienced in the previous stage. The past state is irrelevant. Therefore, Poisson distribution can be used to describe the arrival law of vehicles. Therefore, the Poisson distribution can be used to describe the arrival law of vehicles [25].

Let the vehicle arrival rate be $\lambda, \lambda=\mathrm{q} / 3600$, Then we can know that the arrival rate of vehicles after the bus is $\lambda^{\prime}=q^{\prime} / 3600$.

$$
\lambda^{\prime}=\lambda \frac{\left(\overline{V_{2}}-\overline{V_{1}}\right)}{\overline{V_{1}}}=\lambda \quad\left(1-\frac{\overline{V_{1}}}{\overline{V_{2}}}\right)
$$

$\overline{V_{1}}$ - - The average speed of the bus in the stopping influence area, $\mathrm{km} / \mathrm{h}$

$\overline{V_{2}}$ - - Average speed of subsequent social vehicles arriving, $\mathrm{km} / \mathrm{h}$

The average time that the subsequent social vehicles of the bus are affected by the bus:

$$
t^{\prime}=\frac{1}{\mu^{\prime}-\lambda^{\prime}}
$$

$\mu^{\prime}$ - - Service rate of vehicles that rank behind buses, $p c u / h$

$\lambda^{\prime}$ - - Arrival rate of vehicles behind the bus, $p c u / h$

The average delay time $d$ can be obtained by subtracting the difference between the running time of subsequent social vehicles after being blocked by the bus from the ideal running time.

$$
d=t^{\prime}-\frac{t^{\prime} \overline{V_{1}}}{\overline{V_{2}}}=t^{\prime}\left(1-\frac{\overline{V_{1}}}{\overline{V_{2}}}\right)
$$

The range of impact of parking is the distance from the social vehicle discovering that there is a bus in front of the lane occupied by the bus and preparing to change lanes to overtake the bus to the bus stop, plus the length of the platform parking space of the stop. For the platform of a linear stop, the length of the acceleration area is one body length plus the workshop safety distance. The workshop safety distance is generally 3 meters, so the acceleration space length is set to 15 meters. The space at the back of the stop is the length of the vehicle slowing down and entering the stop. Since the vehicle may arrive at the stop before and after the vehicle, it 
is necessary to add two 18-meter safe parking spaces. Therefore, the length of the platform area can be obtained, and the sum of the length of the bus decelerating into the station, the length of the platform at the stop and the distance away from the station is 48 meters.

Let the travel time of the bus be $t=t_{1}+t_{2}$ ( $t_{1}$ is the stop time, $t_{2}$ is the time from deceleration to stop), The interval of each bus line is $I_{m}$, The number of vehicles arriving in the travel time $\mathrm{t}$ is $\lambda^{\prime} t, \mathrm{~d}$ is the average delay time of each vehicle, and the delay caused by a bus decelerating into the station can be obtained [26].

Assuming that there are $m$ buses at the station, the total delay to social vehicles caused by the slowing down of the buses within 1 hour is:

$$
D=\sum_{m=1}^{n} \frac{60}{I_{m}} \lambda^{\prime} t d
$$

\subsection{Characteristics and Evaluation Indexes of Stop Delay}

The stopping time of the bus at the station accounts for a large proportion of the stopping process. The number of bus doors, the average boarding time per person, and the way of selling tickets will all affect the stopping time of the bus. According to the actual data survey, the total time of opening and closing the door of a bus is generally 3-4 seconds, and the average value of 3.5 seconds is taken in this article.

From the above analysis, it can be seen that the passengers getting on and off the bus are affected by many factors. Refer to the relevant literature to get the time $t$ for getting on and off the passengers [27].

$$
t=\frac{\Omega K t_{0}}{n}
$$

$\Omega$ - Bus capacity, seat/pcu

$K$ - The proportion of total passengers boarding and alighting to the vehicle capacity is usually 0.25 to 0.35 .

$t_{0}$ - The average time it takes for each passenger to get on or off the bus, in seconds, with an average of 2 seconds.

$n$ - Number of bus doors

Therefore, the time model of the bus at the stop can be expressed as:

$$
T=t+3.5=\frac{\Omega K t_{0}}{n}+3.5
$$

The particularity of bus stops is reflected in the fact that only the bus flow in the traffic flow appears to stop and go, that is, the traffic flow has discontinuity and unity, which is also a major reason for the bottleneck of the road section caused by the stop of the bus. The demand for bus stops comes from the frequency of departures and the number of bus lines, while the supply level is reflected in the length of berths, platform area and number of berths. These supply and demand need to be balanced to achieve the maximum effective stop.

The stopping capacity of a bus station is an important parameter to measure the service capacity of the station. The stopping capacity of bus vehicles refers to that under certain road conditions, traffic conditions and road conditions, when public buses arrive at the station one 
after another, The maximum number of vehicles [28] that can be accommodated at this bus stop per unit time. When designing a bus stop, the parking capacity of the bus stop should be used as the basis for judging whether the geometric elements of the stop are reasonable or not. The basic capacity of a bus stop mainly depends on the number of effective parking spaces at the stop, but because the bus is actually operating The dynamic characteristics of the site, the actual capacity of the station is often inconsistent with the basic capacity. The actual capacity of a bus stop mainly depends on the vehicle scheduling plan, the type of bus lane, the type of stop location, and the queuing mode of bus vehicles.

For bus stops near signal-controlled intersections, the US "Traffic Engineering Manual" comprehensively considers the green letter ratio and the stop time of bus vehicles, and combined with the volatility of the arrival of vehicles, the reduction factor $\mathrm{R}$ is calculated in , Generally take $\mathrm{R}=0.833$, you can get the formula for calculating the bus parking capacity of the city bus station [29]:

$$
C_{B M a x}=\frac{\left(\frac{g}{c}\right) 3600 R}{\frac{g}{c} T+t_{b}} \cdot N
$$

\footnotetext{
$C_{B \operatorname{Max}}-$ The maximum number of vehicles that a bus station can accommodate per hour, pcu

$\mathrm{N}$ - - Effective number of parking spaces for multiple parking spaces, number

$\mathrm{g}-$ - Green time, second

c-Cycle duration of each signal cycle, second

$\mathrm{R}$ - - Reduction factor

$\mathrm{T}$ - - The staying time of the bus at the bus stop has been calculated above, that is, the total time spent getting on and off the bus by all passengers, second
}

$t_{b}$ - - The total time it takes for the bus to completely dissipate, that is, the time it takes for the bus to accelerate from a standstill and leave the stop plus the total time until the speed of the bus is consistent with the average speed of the general traffic flow [30].

Determine the effective number of parking spaces $\mathrm{N}$ for multiple parking spaces. For stations that do not clearly divide the stopping positions of each line, when the number of berths is greater than one, the berths cannot be used equally, causing interference between the parking of vehicles, so the use efficiency of the berths at the stop will not reach the ideal $100 \%$.

Table 1. The effective number of berths calculated according to the nature of the linear bus stop

\begin{tabular}{|c|c|c|}
\hline & \multicolumn{2}{|c|}{ Straight bus stop } \\
\hline $\begin{array}{l}\text { Number of } \\
\text { berths(number) }\end{array}$ & Efficient(\%) & $\begin{array}{c}\text { Effective cumulative number of } \\
\text { berths(number) }\end{array}$ \\
\hline 1 & 100 & 1.00 \\
\hline 2 & 85 & 1.70 \\
\hline 3 & 75 & 2.25 \\
\hline 4 & 60 & 2.40 \\
\hline 5 & 50 & 2.50 \\
\hline
\end{tabular}

It can be seen from Table 1 that the effective rate of berths at a stop does not increase linearly with the increase in the number of berths. When there is only one number of berths, the utilization efficiency is $100 \%$, and when the number of berths is increased to 5 , use The 
efficiency plummeted to $50 \%$.

\subsection{Outbound Delay Characteristics and Its Evaluation Index}

Bus vehicles converge when they leave the station after completing the passenger transfer at the harbor-style stop. The delays that exist during this period are called outbound delays. The outbound delay of the harbor-style bus station is based on the calculation of the straight-line station delay, and the outbound delay of the bus is increased. Therefore, the outbound delay of the harbor-style bus station can be analyzed mainly [31].

According to queuing theory and gap acceptance theory, the average waiting time of buses when leaving the station is the product of the average number of non-intervals and the average time of non-intervals.

$$
E(t)=N \times T
$$

$N$ - Average number of waiting intervals for buses, number

$T-$ Non-interval average duration, second

(1) Average number of waiting intervals for buses

$$
n=\frac{1}{e^{-\lambda_{c} \tau_{b}}}-1
$$

$\lambda_{\mathrm{c}}-$ Outer lane traffic flow, $p c u / h$

$\tau_{\mathrm{b}}$ - - The critical gap of the traffic flow of the bus entering the outer lane, second

(2) Non-interval average duration

$$
T=\frac{1+e^{-\lambda_{c} \tau_{b}}}{\lambda_{c}\left(1-e^{-\lambda_{c} \tau_{b}}\right)}
$$

(3) Average outbound waiting time for buses

$$
W=E(t)=\left(\frac{1}{e^{-\lambda_{c} \tau_{b}}}-1\right)\left(\frac{1+e^{-\lambda_{c} \tau_{b}}}{\lambda_{c}\left(1-e^{-\lambda_{c} \tau_{b}}\right)}\right)=\frac{1+e^{-\lambda_{c} \tau_{b}}}{\lambda_{c} e^{-\lambda_{c} \tau_{b}}}
$$

\section{Simulation of Setting Up Bus Main and Auxiliary Stations Based on Anylogic}

\subsection{Space Environment Creation}

Simulation process based on Anylogic: create a new model, build a space environment and build a logical flow, and perform simulation analysis through the software's own data statistics function. Analyze the possible micro-behavior of public transportation vehicles at bus stops, use the road traffic library and pedestrian library in Anylogic to model, and simulate the travel time and average speed of vehicles on a certain length of road through statistical simulation.

The stop in the Anylogic transportation library is a harbor-style station, and subsequent 
vehicles can bypass the bus that is stopping, which is inconsistent with the current Wujiaochang Xiangyin Road Station as a linear station. Therefore, a stop line is set to simulate the Wujiaochang Xiangyin Road station. And the setting of the stop line satisfies the principle of no overtaking.

On this basis, the current platform is optimized. From the current single platform and two parking spaces, the tandem main and auxiliary stations are optimized. The distance between the main and auxiliary stations is 50 meters. After optimization, the distribution of the main and auxiliary stations is shown in Table 2.

Table 2. Optimized bus stop location

\begin{tabular}{|c|c|c|}
\hline Bus routes & Bus stop location & Departure interval \\
\hline Route 453 & Main site & 15 minute / shift \\
\hline Route 133 & Second site & 12 minute / shift \\
\hline Route 406 & Main site & 8 minute / shift \\
\hline Route 325 & Main site & 40 minute / shift \\
\hline Route 405 & Auxiliary site & 20 minute / shift \\
\hline Route 59 & Auxiliary site & 25 minute / shift \\
\hline Route 139 & Auxiliary site & 20 minute / shift \\
\hline
\end{tabular}

\subsection{Logic Flow Construction before Optimization}

When the bus completes the parking service and prepares to leave the station, whether the vehicle parked on berth 2 can leave the station depends on whether there are still vehicles on berth 1. Use the stop line and set the "action-leave" in the stop line properties The logic sentence at time limits the exit conditions of the two berths. Passengers predict the location where the bus will stop, and can choose a parking space to wait. Under the principle of no overtaking, there are a total of 5 strategies for choosing parking spaces when buses enter the station, as shown in Table 3.

Table 3. Vehicle parking location selection strategy before optimization

\begin{tabular}{|c|c|}
\hline Berth occupancy & Vehicle parking location selection \\
\hline Berth 1 is vacant & queue \\
\hline Berth 2 is vacant & Berth 2 \\
\hline Berth 1, Berth 2 are vacant & querth 1 or Berth 2 \\
\hline Berth 1 and Berth 2 are occupied & que \\
\hline
\end{tabular}

By setting the SelecOutput property to restrict the operating state of the bus, set the type of agent such as Car, select the true output "when the condition is true" and set certain conditional statements to judge the oncoming vehicles, so that the bus Vehicles can park at the corresponding berths in accordance with the queuing rules and meet the rules of queuing in order. Set up the Car move to statement and impose conditional restrictions on the actions of vehicles entering and leaving in conjunction with the corresponding stop lines. By setting the pedestrian behavior and combining the position of the vehicle for passenger exchange with the position of the pedestrian waiting for the vehicle, passengers can predict where the bus stops and move in a small area within the platform in advance. As shown in Fig. 1 and Fig. 2 below. 


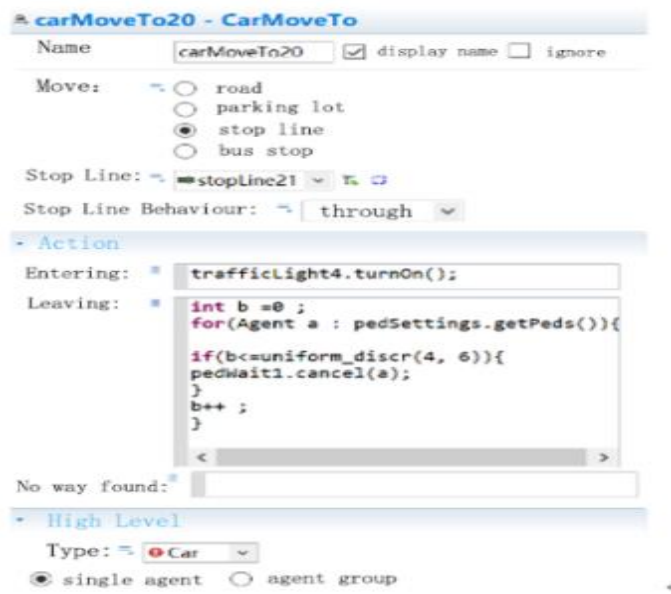

Fig. 1. Passenger exchange after bus entering parking space

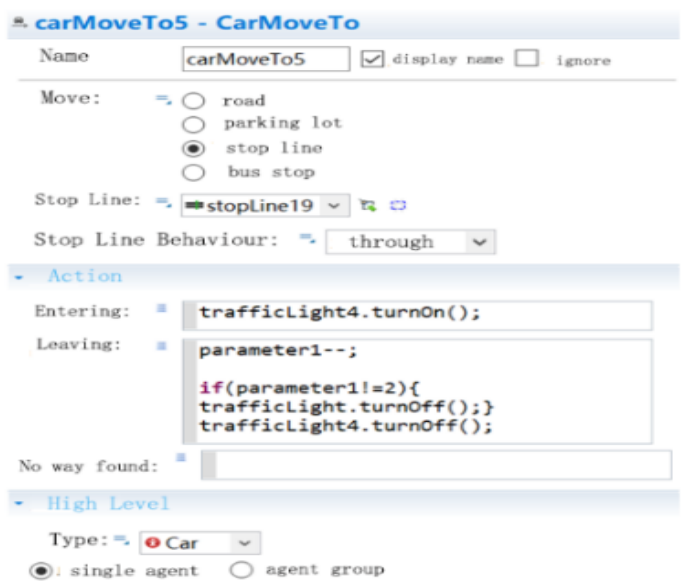

Fig. 2. Conditional statement of bus entering the first parking space

After the bus completes the passenger exchange and leaves the station, it merges into other social traffic, and completes the steps of slowing down and entering the station-performing passenger exchange at the stop-accelerating and leaving the station. The relevant time and speed must be carried out on the road where the vehicle is traveling. Statistics. The road chooses the end position of the forward lane, and counts the relevant data of the agent Car on road6 (the middle ring road), and counts the average time of all vehicles passing the road section.

The logic flow is constructed according to the principles of inbound and outbound, and the logic flow chart before optimization is shown in Fig. 3 below. By setting pedwait, passengers gather in a certain rectangular area and wait in advance. When the vehicle they need to ride in, they will move the passengers through the selectoutput statement, and the passenger flow will be dispersed in the two berths with a certain probability. 


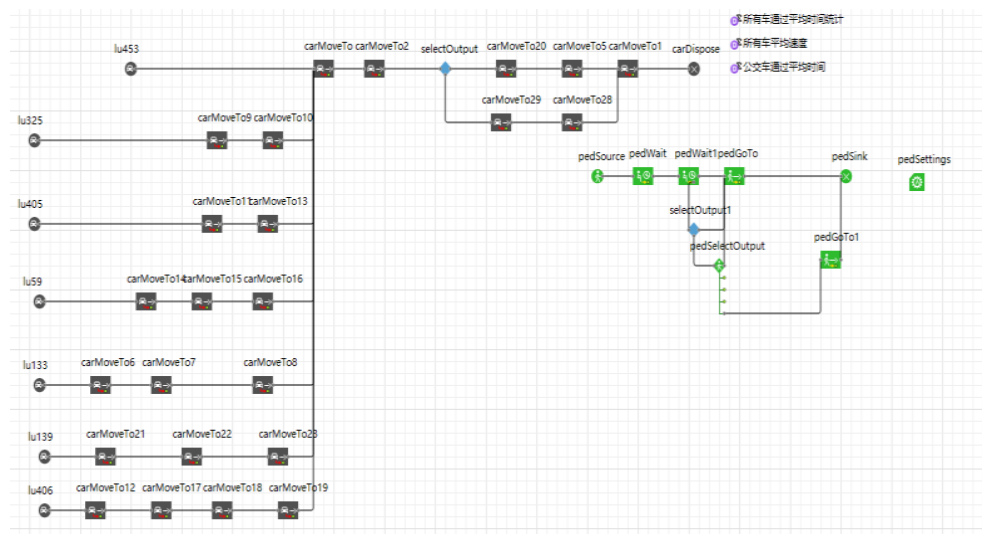

Fig. 3. Logic flow chart before optimization

\subsection{Optimized Logic Flow Construction}

Through the joint application of stop lines and traffic lights in the software, the bus station platform is optimized, and the main and auxiliary bus stations are set, as shown in Fig. 4. The parking parameters and condition statements can be calibrated to achieve the following logic:

(1)When the bus enters the main station (left side) and stops, subsequent vehicles can jump through the left road and stop at the auxiliary station

(2) When the bus enters the secondary station (with side) to stop, subsequent vehicles can enter the main station to stop.

The specific setting process is shown in Fig. 5:

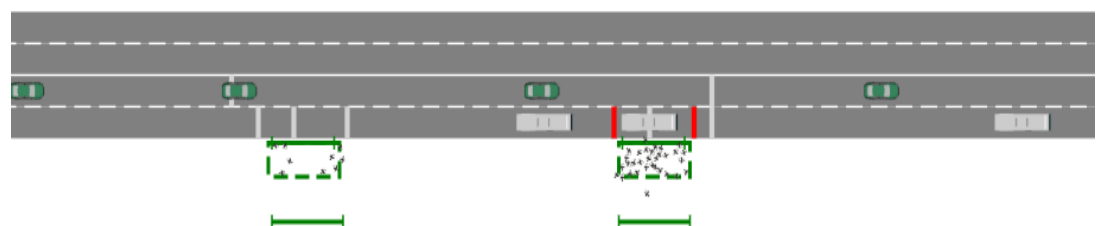

Fig. 4. Schematic diagram of optimized main (left) and auxiliary (right) stations

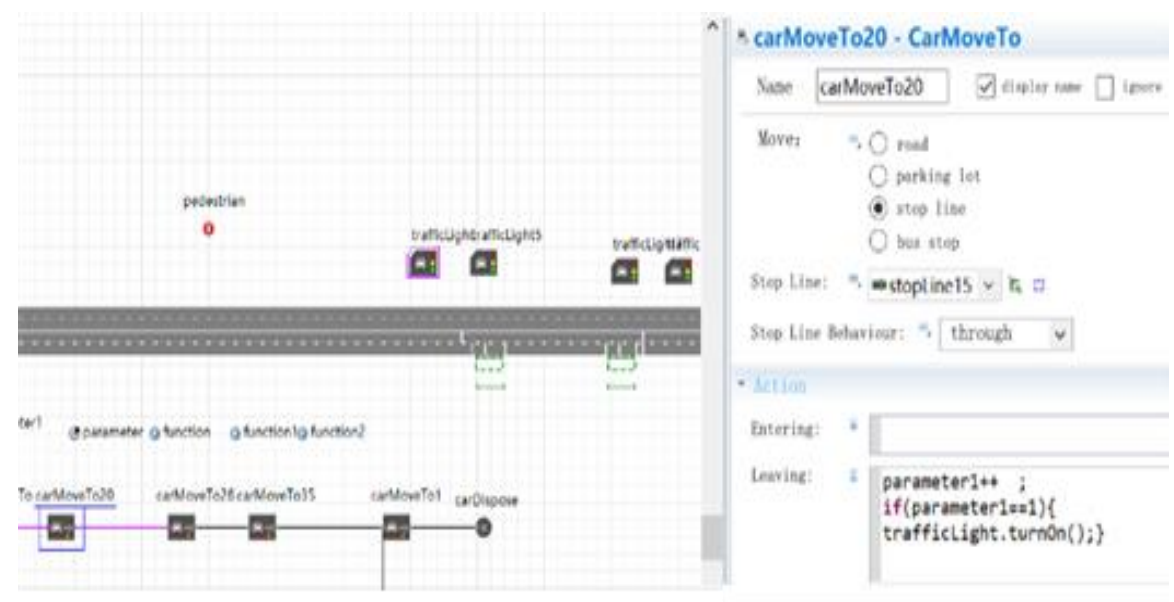

Fig. 5. Logic language setting of optimized bus entering parking space 
After the vehicle enters the berth, the boarding and disembarking of passengers must be completed at the specified location. Passengers can choose to board the bus according to the bus they need to take. Taking the main station as an example, the specific operation process is shown in Fig. 6.

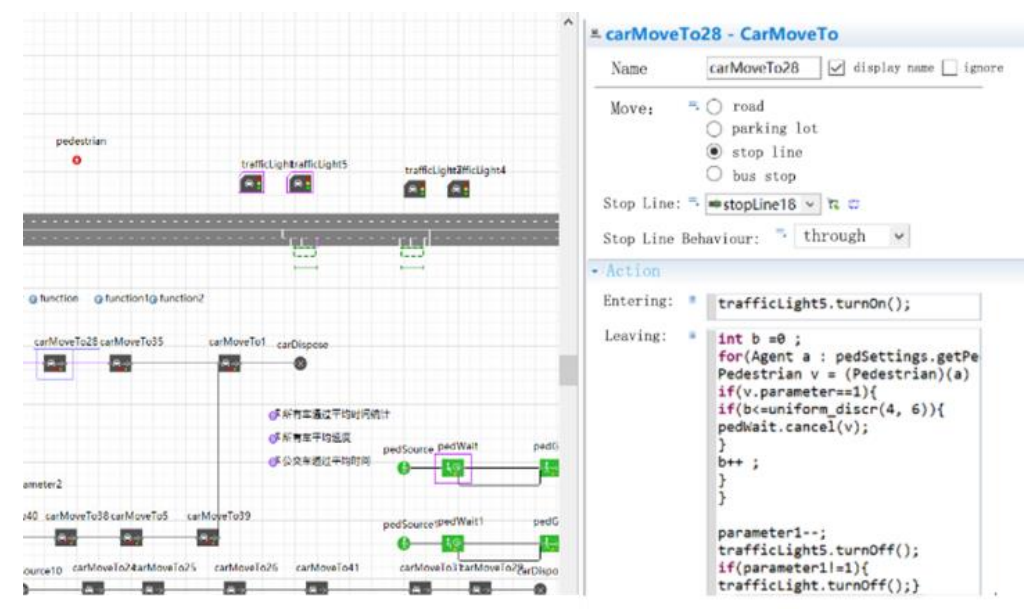

Fig. 6. Logic language setting of optimized bus passenger exchange in parking space

The setting of the main station is the same as that of the secondary station, but in order to distinguish the difference between vehicles and passengers, different parameters parameter2 and pedwait1 need to be set for operation, as shown in Fig. 7.

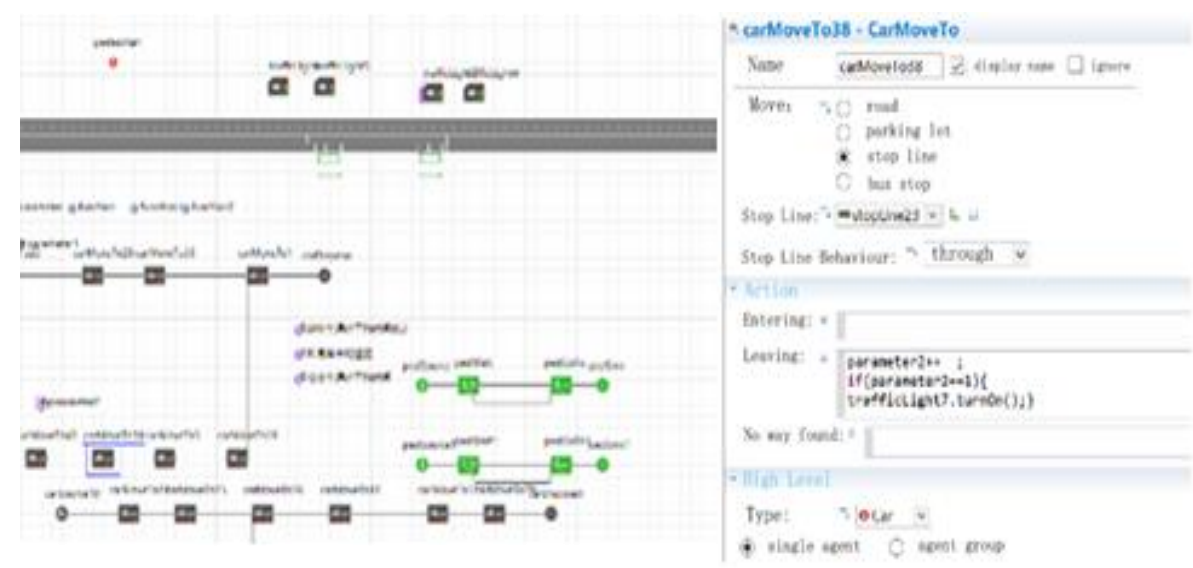

Fig. 7. Using the parameters to make the qualified bus enter the auxiliary station

Add passenger source by setting pedsource and add pedwait to make passengers wait in the designated area. When the bus that the passengers need to take enters the corresponding berth, use pedgoto to make the passengers walk from the waiting area to the designated target line.

After optimization, the stopping position of each line is specified, and the logic flow is constructed according to the optimized entry and exit principles. The optimized overall logic flow chart is shown in Fig. 8. 


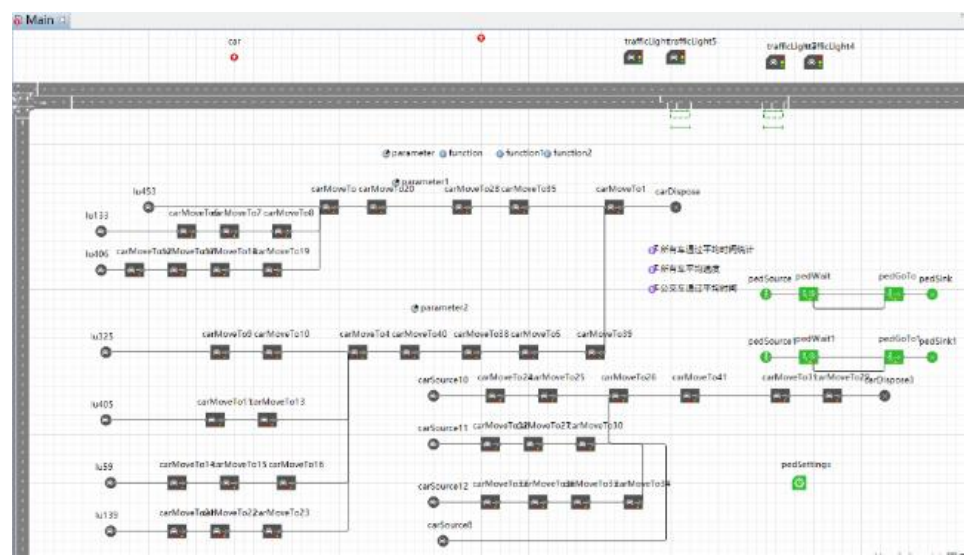

Fig. 8. Logic flow chart after optimization

\section{Output and Analysis of Simulation Results Based on Anylogic}

\subsection{Result Output Analysis Related to the Vehicle}

Select 1000 meters as the observation range of statistical indicators. After running the model for one hour, observe the display results of the data set, and measure the average time (unit: second) of all vehicles before and after optimization and the average speed of all vehicles (unit : $\mathrm{Km} / \mathrm{h}$ ) and the average time (unit: second) of the bus passing the length, as shown in Table 4.

Table 4. Statistics of time and speed before and after optimization

\begin{tabular}{|c|c|c|c|c|c|c|}
\hline & \multicolumn{3}{|c|}{ Before optimization } & \multicolumn{3}{c|}{ Optimized } \\
\hline $\begin{array}{c}\text { Statistical } \\
\text { indicators }\end{array}$ & Mean & Min & Max & Mean & Min & Max \\
\hline CT & 175 & 65.46 & 526.093 & 162.6 & 65.44 & 350.5 \\
\hline CV & 14.74 & 8.8 & 16.67 & 15.93 & 9.76 & 16.67 \\
\hline BT & 180.66 & 129.87 & 262.15 & 164.98 & 137.33 & 244.96 \\
\hline
\end{tabular}

* Note: $C T$ is the average time statistics of all vehicles passing (s), CV is the average speed of all vehicles $(\mathrm{km} / \mathrm{h}), B T$ is the average time passing by public buses $(\mathrm{s})$

It can be seen from Table 3 that the average time for all vehicles to pass is reduced by $7.08 \%$, and the average speed of all vehicles is increased by $8.07 \%$; the average time for buses to pass is reduced by about $8.68 \%$. Although the minimum passing time has increased slightly, the average time and maximum value of all vehicles and buses passing the specified length of $1000 \mathrm{~m}$ before and after optimization have dropped significantly. Therefore, this optimization measure can improve the operating efficiency of most vehicles.

\subsection{Result Output Analysis on Passenger Flow}

The service level of a bus stop can be reflected by the total number of waiting passengers, total waiting time and comfort level, and can also be reflected by indicators such as the average distance between passengers and per capita area. It is known that the area per capita is the ratio of the area of the platform to the maximum number of people waiting at the stop. Table 5 summarizes the limit values of queuing area indicators under different service levels. 
Table 5. Limit value of queuing area index

\begin{tabular}{|c|c|c|}
\hline Service Level & Area per capita $\left(\mathbf{m}^{\mathbf{2}}\right.$ /person) & Average spacing space (m/person) \\
\hline A & $\geqslant 1.2$ & $\geqslant 1.2$ \\
\hline B & $0.9 \sim 1.2$ & $1.1 \sim 1.2$ \\
\hline C & $0.7 \sim 0.9$ & $0.9 \sim 1.1$ \\
\hline D & $0.3 \sim 0.7$ & $0.6 \sim 0.9$ \\
\hline E & $0.2 \sim 0.3$ & $<0.6$ \\
\hline F & $<0.2$ & Very close \\
\hline
\end{tabular}

The width of the optimized docking station platform is 1.1 meters, and verification of the size and service level of the docking station reconstruction after the establishment of the main and auxiliary platforms is required.

Table 6. Calculation of station size

\begin{tabular}{|c|c|c|c|}
\hline \multicolumn{4}{|c|}{ Wujiaochang Xiangyin Road Station } \\
\hline \multirow{6}{*}{$\begin{array}{l}\text { The status of the stop before } \\
\text { optimization }\end{array}$} & direction & \multicolumn{2}{|c|}{ West to east } \\
\hline & Number of berths (piece) & \multicolumn{2}{|c|}{2} \\
\hline & Length of stop ( $\mathrm{m})$ & \multicolumn{2}{|c|}{16.8} \\
\hline & Stop width $(\mathrm{m})$ & \multicolumn{2}{|c|}{1.1} \\
\hline & Stop area $\left(\mathrm{m}^{2}\right)$ & \multicolumn{2}{|c|}{18.5} \\
\hline & $\begin{array}{l}\text { Maximum number of people waiting } \\
\text { (person) }\end{array}$ & \multicolumn{2}{|c|}{37} \\
\hline \multirow{2}{*}{$\begin{array}{c}\text { Calculated data before } \\
\text { optimization }\end{array}$} & Area per capita $\left(\mathrm{m}^{2} /\right.$ person $)$ & \multicolumn{2}{|c|}{0.5} \\
\hline & Service level & \multicolumn{2}{|c|}{$\mathrm{D}$} \\
\hline \multirow{5}{*}{ Optimized } & Auxiliary station settings & $\begin{array}{l}\text { Main } \\
\text { site }\end{array}$ & $\begin{array}{l}\text { Auxiliary } \\
\text { site }\end{array}$ \\
\hline & Design berths (piece) & 1 & 1 \\
\hline & Design length $(\mathrm{m})$ & 15 & 15 \\
\hline & Design area $\left(\mathrm{m}^{2}\right)$ & 16.5 & 16.5 \\
\hline & $\begin{array}{l}\text { Maximum number of people waiting } \\
\text { (person) }\end{array}$ & 14 & 15 \\
\hline $\begin{array}{l}\text { Calculated data after } \\
\text { optimization }\end{array}$ & Design grade & $\mathrm{B}$ & B \\
\hline
\end{tabular}

According to Table 6, the service level of the Wujiaochang Xiangyin Road platform was originally $\mathrm{D}$, and passengers have a poor experience when waiting for buses in the platform waiting area. After the vertical linear main and auxiliary platforms are installed, the passenger flow is also dispersed to a certain extent due to the dispersion of bus lines. The service level is upgraded from the original $\mathrm{D}$ to the $\mathrm{B}$ level, the passenger experience is good, and the platform service level is greatly improved . 


\section{Conclusion}

The optimization and design of urban public transportation stops is one of the main directions of urban public transportation system research. This paper studies the stop characteristics and delay evaluation indicators of public transport in operation. Summarizes several commonly used optimization methods to reduce the delay of public vehicles in the parking area, and uses Anylogic software to simulate the Wujiaochang Xiangyin Road Station, and obtains the most suitable optimization plan for this station through indicators such as vehicle travel time and average speed, To provide a new evaluation method for micro-transportation design such as bus station reconstruction.

Although this article puts forward some suggestions for the optimization of the bus station, but because the vehicles parked at the bus stop do not necessarily follow the principles set by the system, it has its diversity and flexibility and cannot fully simulate the real situation. For pedestrians' choice intentions, only a certain probability is specified in general, and their psychology and preferences are not analyzed. The research results of the article still have many shortcomings, mainly in the following aspects:

Because the data obtained mainly relies on manual methods, it is difficult to obtain a larger amount of accurate data, and the form of data processing is relatively simple. In future research, you can make full use of big data resources and combine with data analysis software. Do more in-depth research.

For pedestrians' choice intentions, they only generally stipulate the probability of pedestrians' arrival, boarding, and dispersion, without analyzing their psychology and preferences, which makes a certain deviation in the judgment of delay.

This article only discusses from a theoretical point of view that optimization can improve the current situation of the Wujiaochang Xiangyin Road platform, reduce delays, and improve platform capacity. However, if it is necessary to decide whether to optimize the actual platform by setting up the main and auxiliary platforms, it is necessary to conduct a comprehensive analysis and draw conclusions in combination with multiple disciplines such as transportation economics and urban planning. For the optimization design of urban multi-line bus stops, there are many aspects that can be studied in depth.

\section{Acknowledgement}

This work is funded by National Key Research and Development Program of China (2019YFC1511000), National Natural Science Foundation of China (61772454), National Key Research, Development Program of China (2019YFC1511000) and Humanities and Social Sciences Fund of the Ministry of Education(weiwei liu).

\section{References}

[1] W. W. Liu, "Analysis on Parking Sharing Capacity Based on Supply-Demand Relationship," Journal of Internet Technology, vol. 21, no. 5, pp. 1253-1262, Sep. 2020. Article (CrossRef Link)

[2] S. C. Wirasinghe and N. S. Ghoneim, "Spacing of Bus-Stops for Many to Many Travel Demand," Transportation Science, vol. 15, no. 3, pp. 2-12, Aug. 1981. Article (CrossRef Link)

[3] J. Wang, Y. Yang, T. Wang, R. S. Sherratt, and J. Zhang, "Big Data Service Architecture: A Survey," Journal of Internet Technology, vol. 21, no. 2, pp. 393-405, 2020.

$\underline{\text { Aritcle (CrossRef Link) }}$ 
[4] J. Zhang, S. Zhong, T. Wang, H. C. Chao, and J. Wang, "Blockchain-Based Systems and Applications: A Survey," Journal of Internet Technology, vol. 21, no. 1, pp. 1-14, 2020. Article (CrossRef Link)

[5] S. Zhang, Y. Chang, L. Yan, Z. Sheng, F. Yang, G. Han, Y. Huang, and J. Xia, "Quantum Communication Networks and Trust Management: A Survey," Computers, Materials \& Continua, vol. 61, no. 3, pp. 1145-1174, Jan. 2019. Article (CrossRef Link)

[6] J. Wang, Y. Gao, W. Liu, W. Wu, and S. J. Lim, "An Asynchronous Clustering and Mobile Data Gathering Schema Based on Timer Mechanism in Wireless Sensor Networks," Computers, Materials \& Continua, vol. 58, no. 3, pp. 711-725, Jan. 2019. Article (CrossRef Link)

[7] W. Han, Z. Tian, Z. Huang, L. Zhong, and Y. Jia, "System Architecture and Key Technologies of Network Security Situation Awareness System YHSAS," Computers, Materials \& Continua, vol. 59, no. 1, pp. 167-180, Jan. 2019. Article (CrossRef Link)

[8] M. Waqas, S. Tu, S. U. Rehman, Z. Halim, S. Anwar, G. Abbas, Z. Abbas, and O. Rehman, "Authentication of vehicles and road side units in intelligent transportation system," Computers, Materials \& Continua, vol. 64, no. 1, pp. 359-371, Apr. 2020. Article (CrossRef Link)

[9] L. Lin, "Study on Optimization Design of Bus Stop," Southeast University, 2006.

[10] W. W. Liu, Y. Tang, F. Yang, C. Zhagn, D. Cao, and G. J. Kim, "Internet of Things Based Solutions for Transport Network Vulnerability Assessment in Intelligent Transportation Systems," Computers, Materials \& Continua, vol. 65, no. 3, pp. 2511-2527, Sep. 2020. Article (CrossRef Link)

[11] H. W. Ge, "Traffic Effect Analusis and Optimization Techniques of Bus Stop," Southeast University, 2006.

[12] Y. Zhang, Y. Deng, Y. Liu, and L. Wang, "Dynamics Modeling and Stability Analysis of Tilt Wing Unmanned Aerial Vehicle During Transition," Computers, Materials \& Continua, vol. 59, no. 3, pp. 833-851, Jan. 2019. Article (CrossRef Link)

[13] X. Nie, X. Zou, and D. Zhu, "Modeling and simulation of entrepreneur individual based on dynamic and complex system computing," Computer Systems Science and Engineering, vol. 34, no. 4, pp. 207-214, Jan. 2019. Article (CrossRef Link)

[14] J. Zhang, "Personalized product recommendation model based on user interest," Computer Systems Science and Engineering, vol. 34, no. 4, pp. 231-236, Jan. 2019. Article (CrossRef Link)

[15] S. C. Wirasinghe and N. S. Ghoneim, "Space of Bus-stops for Many Travel Demand," Transportation Science, vol. 15, no. 3, pp. 175-293, 1981. Article (CrossRef Link)

[16] A. A. Saka, "Model for Determining Optimum Bus-stop Spacing in Urban Areas," Journal of Transportation Engineering, vol. 128, no. 6, pp. 195-199, Nov. 2002. Article (CrossRef Link)

[17] H. Gao, W. Huang, and X. Yang, "Applying Probabilistic Model Checking to Path Planning in an Intelligent Transportation System Using Mobility Trajectories and Their Statistical Data," Intelligent Automation and Soft Computing, vol. 25, no. 3, pp. 547-559, Jan. 2019. Article (CrossRef Link)

[18] J. Liu, X. Kang, C. Dong, and F. Zhang, "Simulation of Real-Time Path Planning for Large-Scale Transportation Network Using Parallel Computation," Intelligent Automation and Soft Computing, vol. 25, no. 1, pp. 65-77, Jan. 2018. Article (CrossRef Link)

[19] J. Li, H. Li, G. Cui, Y. Kang, Y. Hu, and Y. Zhou, "Gacnet: a generative adversarial capsule network for regional epitaxial traffic flow prediction," Computers, Materials \& Continua, vol. 64, no. 2, pp. 925-940, Jan. 2020. Article (CrossRef Link)

[20] A. A. Saka, "Effect of Bus-Stop Spacing on Mobile Emissions in Urban Areas," in Proc. of the 82 $2^{\text {nd }}$ Transportation Research Board Annual Meeting, 2003. Article (CrossRef Link)

[21] S. Yagar and M. Jacques, "Representing the effects of transit stops at signalized intersections," in Proc. of the International Symposium on Highway Capacity, pp. 485-492, 1991. Article (CrossRef Link)

[22] R. Z. Koshy and V. T. Arasan, "Influence of Bus Stops on Flow Characteristics of Mixed Traffic," Journal of Transportation Engineering, Part A: Systems, vol. 131, no. 8, pp. 640-643, Aug. 2005. $\underline{\text { Article (CrossRef Link) }}$ 
[23] D. Kim and S. Kim, "Network-aided intelligent traffic steering in 5g mobile networks," Computers, Materials \& Continua, vol. 65, no. 1, pp. 243-261, Jan. 2020. Article (CrossRef Link)

[24] Y. Wang, Y. Cao, L. Zhang, H. Zhang, R. Ohriniuc, G. Wang, and R. Cheng, "YATA: Yet another Proposal for Traffic Analysis and Anomaly Detection," Computers, Materials and Continua, vol. 58, no. 2, pp. 1171-1187, Jan. 2019. Article (CrossRef Link)

[25] W. Wang, S. M. Qin, X. K. Tian, J. W. Zhang, and F. X. Li, "Queue Delay Model and Simulation for TTCAN," Advanced Materials Research, vol. 1006, no. 1007, pp. 707-710, Aug. 2014. Article (CrossRef Link)

[26] Y. Huang, "Analysis on the Effects of Inbound Bus Based on Queuing Theory," Beijing Jiaotong University, pp. 25-35, 2010.

[27] T. Liu, "Multi-line Bus Stop Platform Size Optimization and Organization Design," Jilin University, 2018.

[28] F. Xio, "Survey and Analysis of Bus Delay in Bus Stop," Urban Transport of China, pp. 69-71, 2004. Article (CrossRef Link)

[29] K. S. Li, "Study on Layout of Multiple Routes Bus Stop," Beijing Jiaotong University, 2008.

[30] CJJ37-2012, "Urban Road Engineering Design Code," Beijing: Ministry of Housing and UrbanRural Development of the People's Republic of China, 2012. Article (CrossRef Link)

[31] W. Liu, Y. Tang, F. Yang, Y. Dou, and J. Wang, "A Multi-Objective Decision-MakingApproach for the Optimal Location of Electric Vehicle Charging Facilities," Computers, Materials \& Continua, vol. 60, no. 2, pp. 813-834, 2019. Article (CrossRef Link) 


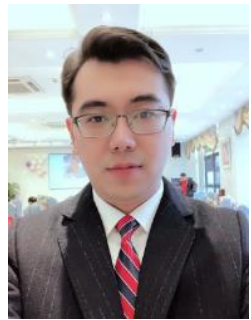

Weiwei Liu is working in Business School, University of Shanghai for Science and Technology. He has presided over and participated in a number of National Natural Science Foundation projects, etc. He has published 40 academic papers in international academic journals, of which more than 20 papers have been retrieved in SCI andEI.

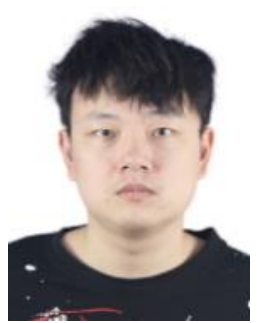

Fu Wang is currently studying in Business School, University of Shanghai for Science and Technology, Anhui, China. His graduate major is transportation. His research direction is transportation planning and management.

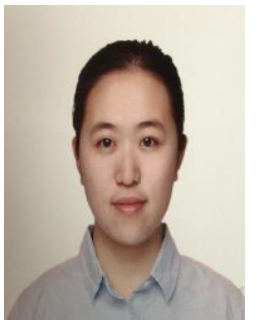

Chennan Zhang is currently studying in Business School, University of Shanghai for Science and Technology, Shanghai , China. Her research interest includes Traffic Engineering and Traffic Planning.

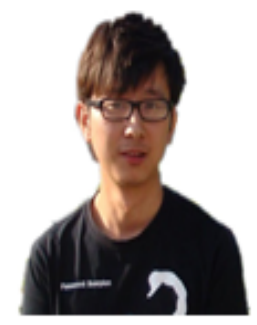

Jingyu Zhang received the Ph.D. degree in Computer Science and Technology from Shanghai Jiao Tong University in 2017. He is currently an Assistant Professor at the School of Computer \& Communication Engineering, Changsha University of Science and Technology, China. His research interests include computer architecture, mobile computing and blockchain.

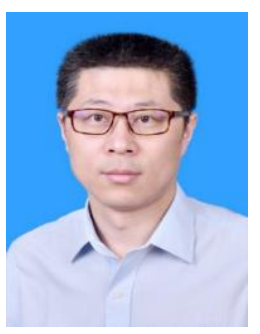

Lei Wang received the B.E, M.E and Ph. D. degrees from Changsha University of Science \& Technology, China in 2002, 2005 and 2008, respectively. He is a professor at Changsha University of Science and Technology. He has published more than 160 journal and conference papers. His research interests mainly include uncertainty quantification, system reliability of structures, and safe operation risk control of traffic network. 